\title{
Editorial
}

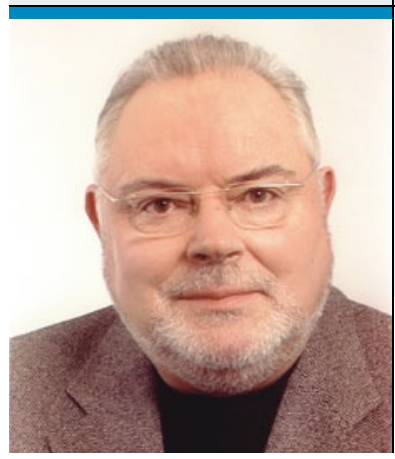

"Den Staffelstab als Chefredakteur zu übergeben, bedeutet keinen Ruhestand für mich, sondern weiterhin tatkräftige Mitarbeit für Ihre gewohnten HNO-Nachrichten."

Dr. med. Dieter Leithäuser

Chefredaktion und HNO-Arzt, Warburg

\section{As time goes by ...}

D

ieses Lied singt der Pianist Sam in "Casablanca“ für Ingrid Bergmann. Der Berliner würde singen: „Kinder, ist die Zeit doch schön, ohne ins Büro zu geh ' $n$ ". Die Worte treffen nach dieser Ausgabe der HNONachrichten auch auf mich zu: Seit 1990 bin ich dieser Zeitschrift eng verbunden, immerhin 13 Jahre als Chefredakteur haben meine Redaktionsmannschaft und ich versucht, Kollegen mit Praxiswissen und zeitgemäßen Fortbildungsbeiträgen zu versorgen. Einen wichtigen Anteil daran hatte der kompetente Beirat dieser Zeitschrift - danke an alle, die mitgeholfen haben!

Drei Verlagsgruppen habe ich miterlebt. Angefangen mit eigenen Schwarz-Weiß-Strichabbildungen war der Übergang in das Zeitalter der digitalen Farbe nicht immer einfach, das zeigte sich schon in der nicht immer gelungenen Gestaltung der Titelbilder. Nun ist es Zeit für mich nach der Beendigung meiner aktiven Praxistätigkeit im weisen 70-er-Alter in der Kette der Hierarchie etwas zurückzutreten.

Der geschätzte Kollege Gerd Grevers aus Starnberg wird meine Tätigkeit als Chefredakteur übernehmen ein Wunschkandidat. Meine Person wird in den Redaktionsbeirat überwechseln. Das bedeutet keinen Ruhestand für mich, sondern weiterhin tatkräftige Mitarbeit für Ihre gewohnten HNO-Nachrichten. „Ich bin dann mal weg“, wie der Komiker Hape Kerkeling im Titel seines Pilgerbuches ankündigt, trifft auf mich also nicht zu.

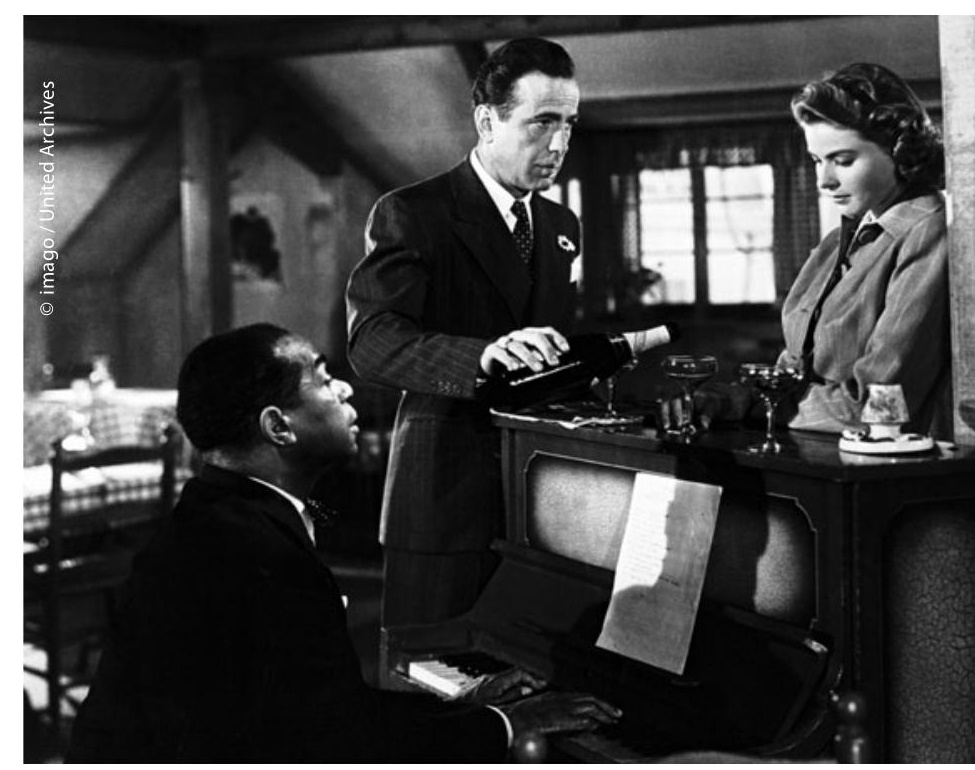

Die HNO-Nachrichten werden wie bisher ein gehegtes Pflänzchen in meinem Garten sein. Bleiben Sie uns auch weiterhin als treue Leser erhalten!

Das wünscht sich Ihr

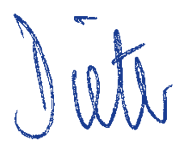

